\title{
Urodimento
}

REVISTA DE ESTUDOS EM ARTES CÊNICAS

E-ISSN 2358.6958

\section{(Trans)formações do palhaço: Breve história dos tipos clássicos da palhaçaria}

Jonathan Brites Sena

Natássia Duarte Garcia Leite de Oliveira

\section{Para citar este artigo:}

SENA, Jonathan Brites; OLIVEIRA, Natássia Duarte Garcia Leite de. (Trans)formações do palhaço: breve história dos tipos clássicos da palhaçaria. Urdimento

- Revista de Estudos em Artes Cênicas, Florianópolis, v. 2, n. 41, set. 2021. 


\title{
(Trans)formações do palhaço: \\ Breve história dos tipos clássicos da palhaçaria ${ }^{1}$
}

Jonathan Brites Sena²

Natássia Duarte Garcia Leite de Oliveira ${ }^{3}$

\begin{abstract}
Resumo
O presente artigo é um recorte atualizado da pesquisa (Trans)Formações do Palhaço: História dos Tipos e Técnica na Arte da Palhaçaria (2014). A investigação buscou compreender a constituição da figura do palhaço. Por meio de diversas referências. Os principais tipos clássicos, especialmente a dupla cômica Branco e Augusto e o ContraAugusto, identificando algumas de suas características. Acredita-se que a diversidade encontrada em diversos contextos influenciou as concepções de palhaço presentes na contemporaneidade. Com essa contribuição é possível, portanto, refletir sobre como a arte da palhaçaria vem se desenvolvendo culturalmente.
\end{abstract}

Palavras-chave: Artes da cena. Artes circenses. Palhaçaria. Palhaço. Tipos cômicos.

\section{(Trans)formations of the clown: Brief history of classic types of clowning art}

\begin{abstract}
This article updates results on the research (Trans)formations of the clown: History of Types and Techniques of Clowning Art (2014). This research aimed to understand the constitution of the clown character. Through various references. main classic types were presented, the comic duo White clown and Auguste, and the Contra-Auguste, while identifying some of their characteristics. Itis supposed that the diversity found in different contexts has influenced the ways the clown is conceived today. This contribution makes thus possible to reflect on the cultural development of clowning art.
\end{abstract}

Keywords: Performing arts. Circus arts. Clowning art. Clown. Comic types.

1 Artigo revisado por Ana Paula Ribeiro de Carvalho, graduada em Letras pela Universidade Federal de Goiás (UFG), especialista em Revisão de Texto e mestra em Literatura e Crítica Literária pela Pontifícia Universidade Católica (PUC-GO)

2 Mestrando em Artes da Cena na Escola de Música e Artes Cênicas da Universidade Federal de Goiás (UFG). Especialista em Educação Física Escolar pela Universidade Federal de Catalão (UFCAT). Graduação em Artes Cênicas pela UFG. Professor do Núcleo de Atividades Complementares (NAC) do Colégio Marista de Goiânia. jonathan.sena17@hotmail.com

(9) http://lattes.cnpq.br/5550764182376111

(iD) https://orcid.org/0000-0002-2354-310X

${ }^{3}$ Doutorado pelo Programa de Pós-Graduação da Faculdade de Educação da Universidade Federal de Goiás (UFG). Mestrado em arte pela Universidade de Brasília (UnB) e Bacharel em Artes Cênicas ambos pela mesma Universidade. Professora dos cursos de graduação em teatro e direção de arte; e do Programa de Pósgraduação em Artes da Cena - UFG. natassiagarcia@ufg.br

(9) http://lattes.cnpq.br/2673206479757870 $\quad$ (iD https://orcid.org/0000-0003-1744-2035 
(Trans)formaciones del payaso:

breve historia de tipos clásicos del arte del payaso

\section{Resumen}

Este artículo es un extracto actualizado de la investigación (Trans) Formaciones del payaso: historia de tipos y técnicas en el arte del payaso (2014). La investigación buscó comprender la constitución de la figura del payaso. A través de varias referencias presentamos los principales tipos clásicos, especialmente el dúo cómico Carablanca y Augusto y el Contra-Augusto, identificando algunas de sus características. Suponemos que la diversidad encontrada en diferentes contextos ha influido en los conceptos de clown presentes en nuestra contemporaneidad. Con tal aporte, es posible, por tanto, reflexionar sobre cómo se ha ido desarrollando culturalmente el arte del clown.

Palabras clave: Artes escénicas. Artes circenses. Arte del payazo. Payazo. Tipos cómicos. 
O presente artigo é um desdobramento da pesquisa intitulada (Trans) Formações Do Palhaço: História Dos Tipos e Técnica na Arte da Palhaçaria4. Desenvolvido pelo Prof. Esp. Jonathan Brites Sena e, orientado pela Profa. Dra. Natássia Duarte Garcia Leite de Oliveira. O Trabalho de Conclusão de Curso foi defendido no ano de 2014, para obtenção do título de licenciado em Artes Cênicas, pela Escola de Música e Artes Cênicas da Universidade Federal de Goiás (EMAC/ UFG).

A investigação busca compreender a historicidade acerca do palhaço, contextualizando-o em diferentes tempos da história para melhor entender e analisar a constituição da arte da palhaçaria, sob uma perspectiva sócio-históricacultural. Neste sentido, foram expostos diversos e distintos tipos cômicos ${ }^{5}$ presentes em algumas sociedades; tipos cômicos sagrados pertencentes a diferentes tribos e; os bufões e bobos da corte da Idade Média. Buscou-se ainda, trazer os principais tipos clássicos de palhaços, a dupla cômica 'Branco e Augusto' e o Contra-Augusto, identificando suas características específicas. Acredita-se que toda essa diversidade influenciou as concepções de palhaço presentes na contemporaneidade. Desta forma, os objetivos são: analisar e refletir criticamente sobre como a arte da palhaçaria vem se desenvolvendo culturalmente; e colaborar para a difusão do conhecimento acerca das modalidades que constituem as artes circenses e também integram o campo das artes da cena.

Neste artigo, não há a pretensão de se categorizar os tipos cômicos com definições fechadas e inflexíveis. Ao contrário, buscou-se aqui, mostrar as linhas tênues entre os tipos cômicos e um panorama de possibilidades criativas e expressivas destes. O intuito era reconhecer os principais legados e suas

\footnotetext{
${ }^{4}$ A pesquisa com a palhaçaria se iniciou em 2010 e está disponível no terceiro capítulo do Trabalho de Conclusão de Curso (Trans)Formações do Palhaço: História dos Tipos e Técnica na Arte da Palhaçaria, escrito por Jonathan Sena e orientado por Natássia Oliveira (2014). A arte da palhaçaria é um campo ainda com pouco material de pesquisa, portanto, em breve os autores farão publicações específicas acerca dos conceitos e das categorias que envolvem o tema.

${ }^{5}$ O cômico não se limita ao gênero da comédia; é um fenômeno que pode ser apreendido por vários ângulos e em diversos campos [...]. O cômico se nos apresenta através de uma situação, um discurso, um jogo de cena de modo ora simpático, ora antipático. No primeiro caso, zombamos com comedimento daquilo que percebemos como engraçado, divertido; no segundo, rejeitamos como ridícula (risível) a situação que nos é apresentada (Pavis, 1999, p. 58, 60). Será utilizada a dimensão do que é cômico, humorístico e risível.
} 
influências na arte do palhaço na atualidade, palhaço que se solidifica no circo tradicional ou no circo moderno.

\section{Da arquitetura do circo e da arqueologia do cômico: O circo moderno e a figura emergente do palhaço}

O chamado circo moderno ou circo tradicional, ainda mantém o picadeiro ${ }^{6}$ e uma estrutura em formato circular, com números que geram tensão na plateia. Inferiu-se que essa forma clássica de se referir às artes circenses, surgiu por volta de 1770, mais precisamente em 1779, com o oficial da cavalaria britânica Philip Astley $^{\top}$ (1742 - 1814). O picadeiro de circo oficial mede 13 metros devido a uma descoberta de Astley. Ele concluiu que, se amarrasse a ponta de uma corda de 13 metros em um mastro fixo e a outra ponta em um cavalo, teria, assim, um ângulo circular perfeito para conseguir realizar a façanha de permanecer montado em pé no lombo de um cavalo em movimento. Vários números com cavalos eram apresentados no espetáculo do oficial Astley e a composição estrutural era completamente militar, com uso de uniformes, rufar de tambores e utilização de armas, porque apenas com o hipismo o espetáculo se tornava monótono (Bolognesi, 2003).

Assim sendo, Astley, ao perceber a importância da dinâmica em seus números para atrair a atenção do público, decidiu inserir em seus espetáculos diversas acrobacias, tais como:

[...] volteios de cavalos livres, que obedeciam à voz do comando de um treinador, executando evoluções, com ou sem obstáculos, cavalos montados por acrobatas que executavam saltos, pirâmides e outras evoluções em seu dorso e pantomimas envolvendo cenas militares (Bolognesi, 2003, p.32).

Todos esses elementos agregados ao espetáculo de Astley geraram um maior interesse do público. O próprio Astley dirigia e apresentava o espetáculo, criando, assim, a figura do mestre de cerimônia ou mestre de pista, que ainda é tão

${ }^{6}$ Espaço destinado às apresentações dos números dos circenses dentro da lona do circo.

${ }^{7}$ Atribui-se ao suboficial da cavalaria inglesa, Philip Astley, a criação do circo moderno. Ele construiu um edifício permanente em Londres, em Westminster Bridge, chamado Anfiteatro Astley. 
presente nos espetáculos tradicionais de circo. Originalmente, o mestre de pista era o domador dos animais e também o diretor dos números equestres. Com o tempo, assumiu a função de mestre de cerimônia, que hoje é conhecido como apresentador.

O Mestre de Pista também participava das entradas circenses, quase sempre trazendo a lucidez à cena, característica ausente no palhaço. Antes mesmo de se fixar a dupla cômica, o Mestre de Pista se transformou em uma espécie de soberano do Clown (Bolognesi, 2003, p. 68).

O aumento do interesse do público pelas apresentações no circo de Astley, somado às condições climáticas desfavoráveis à realização do espetáculo a céu aberto, evidenciou a necessidade de investimento em uma cobertura no lugar onde ocorriam os números. Observando-se as contribuições mais atuais da autora Ermínia Silva (2008), não se sabe, ao certo, se Astley foi, efetivamente, o criador da proposta da lona do circo. Isso, porque outras pessoas e grupos também estavam fazendo adaptações semelhantes. Todavia, pode-se afirmar que houve uma mudança significativa no espaço cênico e que - na história do circo tal como se conhece - Astley se tornou a principal referência com relação a essa transformação. Destarte, ele transferiu suas apresentações para um ambiente fechado, arquitetonicamente pensado para suas especificidades, mais confortável à plateia e que possibilitava a cobrança de ingresso.

Com as dificuldades de se apresentar a céu aberto, por causa das variações do tempo, em 1779, Astley construiu um anfiteatro permanente e coberto em madeira, o Astley Royal Amphitheater of Arts, que também comportava uma pista cercada por arquibancadas. [...] Quanto à plateia [sic], camarotes e galerias foram colocados em andares superpostos, inclusive camarotes no proscênio, e não mais em arquibancadas. Esta combinação permitia dar espetáculos maiores do que pantomimas de pista, e o público podiam assistir inteiramente às apresentações, tendo em vista a sua disposição ao redor e em lugares de cima a baixo, ao lado da pista e do palco (Silva, 2008, p.35 - 36).

8 Sobre o clown, Dario Fo diz: "O clown vem de muito longe: eles já existiam antes do nascimento da Commedia dell'Arte. Podemos dizer que as máscaras à italiana nasceram de um casamento obsceno entre jogralescas, fabuladores e clowns; e, posteriormente, depois de um incesto, a Commedia pariu dezenas de outros clowns " (Fo, 1998, p. 305). Nesta citação, o autor afirma que o palhaço possui herança dos tipos cômicos, tipos estes que contribuem direta ou indiretamente com a construção do palhaço que conhecemos hoje, mas com o tempo são dados vários nomes a essa figura. 
Percebe-se com a citação de Silva (2008), que Astley era um visionário, atento às necessidades técnicas de seu ofício. De acordo com Mário Fernando Bolognesi (2003), o circo moderno, portanto, é resultado da conjunção de dois universos espetaculares até então distintos: de um lado, a arte equestre inglesa, que era desenvolvida nos quartéis; de outro, as proezas dos saltimbancos. Essa convenção do espaço cênico, no qual acontecem os atos circenses, assim como sua composição espetacular, deu origem ao que se chama "circo moderno". Tal estrutura formal ganhou o mundo rapidamente, primeiramente em toda a Europa, e depois no mundo. Segundo Silva (2008), o circo moderno chegou ao Brasil no final do século XVIII, graças à migração das famílias circenses europeias e norteamericanas, as quais percorreram todo o país. Essas trupes assumiram uma característica nômade e realizavam constantes turnês por onde passavam, adaptando-se de acordo com cada região, cultura ou país.

O circo moderno acolheu os artistas de rua e feiras, abrigou-os em uma organização de trabalho, fomentou uma melhor estrutura para as apresentações e possibilitou uma produção com a organização de uma plateia e cachês/remuneração pela apresentação. Com este movimento, acrobatas, funâmbulos, ilusionistas, cômicos, dentre outros, poderiam se apresentar com melhores qualidades de trabalho.

A virtuose sempre esteve presente durante os espetáculos, gerando êxtase no público ao presenciar tamanhas qualidades corporais que "desafiam" a própria física. O risco sempre se manteve presente e oferecia a real possibilidade de ser mortal, desde os volteios dos acrobatas, a agilidade dos malabaristas, a força dos trapezistas ou a apreensão pelos equilibristas. Dentre as variedades de apresentações, destacou-se a figura do cômico, posteriormente nominado de palhaço.

O público vivenciava apresentações sobre-humanas, com a apreciação de super-forças, super-velocidades e, super-equilíbrios. Em oposição, o palhaço trouxe para a arena a estupidez, o fracasso, o erro e o ridículo, aproximando-se daquilo que é humano. A plateia podia se reconhecer nas apresentações dos 
palhaços, identificando-se com algumas situações inusitadas, nas quais o riso ${ }^{9}$ era uma potencialização do próprio ridículo.

Nesse contexto, o palhaço assumiu um importante papel dentro da estrutura de apresentações circenses, exercendo o trabalho de alinhavar os números e ocupando os espaços entre os números. A função do cômico era entrar em cena após cada apresentação, satirizando e ironizando os números já apresentados; ou apresentar números autorais, tirando sarro da própria plateia. Proporcionava-se, assim, tanto um lugar de resistência como alguns momentos de diversão, anestesiando um pouco os problemas existentes individualmente e até mesmo socialmente.

Desse modo, rapidamente, os palhaços, assumiram um papel de protagonismo no cenário circense e ganharam reconhecimento mundial no circo moderno, sendo considerados como a alma do circo. Mas será que a figura do palhaço nasceu do circo?

\section{O riso d'alma: em busca de uma gênesis do palhaço}

Culturalmente, quase sempre, a figura do palhaço está relacionada ao circo. É notória a relevância do palhaço para o universo circense e que foi no circo que o palhaço adquiriu um status socialmente, ganhando um papel de destaque e tornando-se mais popular. Entretanto, acredita-se que a origem do palhaço se remonta antes mesmo do circo moderno, em diferentes contextos culturais.

Imagino que o primeiro palhaço surgiu numa noite qualquer em uma indefinida caverna enquanto nossos antepassados terminavam um lauto banquete junto ao fogo. Em volta da fogueira, numa roda de companheiros, jogavam conversa fora. Comentavam a caçada que agora era jantar e falavam das artimanhas usadas, dos truques e da valentia de cada um. É quando um deles começa a imitar os amigos e exagera nas atitudes do valentão que se faz grande, temerário e risível na sua ânsia de sobrepujar a todos. E logo passa a representar as momices do covarde, seus cuidados para se esquivar dos combates, sempre exagerando os gestos, abusando das caretas, apontando tão absurdamente as intenções por trás de cada ação e o ridículo se instala naquela assembléia [sic] de trogloditas. E todos descobrem o prazer de rir entre companheiros, de rir

${ }^{9}$ Para aprofundamento do conceito de riso, ver Henri Bergson (2007). 
de si mesmo ao rir dos outros (Castro, 2005, p. 12).

Alice Viveiros de Castro (2005) leva a perceber que o sentido cômico é inerente ao ser humano. E, na medida em que a humanidade exerce sua potencialidade de comicidade, ela também a imprime em suas relações - com o mundo, a natureza e seus pares.

Nesse movimento, Castro (2005) traça um panorama acerca dos tipos cômicos na antiguidade e traz como exemplos rituais dos povos astecas, que, em suas manifestações, usavam da bufonaria com imitações de aleijados, corcundas e anões, provocando hilaridade ${ }^{10}$. Essa era uma das maneiras utilizadas pela sociedade da época para se proteger do medo e do mal. Outro exemplo é a cerimônia Egun-gun realizada na cultura Iorubá, a qual criou seis máscaras, que são representações de: um corcunda, um albino, um leproso, um prognata, um anão e um aleijado. Todas as figuras estão presentes entre os bufões e têm referências nas questões das diferenças corpóreas.

Castro (2005) também relata sobre os índios norte-americanos que possuem a figura dos Heyokas. Sua principal função é lembrar a tribo sobre o absurdo dos comportamentos humanos e a necessidade de não levar as regras demasiadamente a sério. A pesquisadora ainda cita os monges budistas tibetanos, que têm a figura do Mi-tshe-ring, um velho bufão sábio, que atrapalha todas as cerimônias religiosas, sendo incapaz de fazer silêncio.

Outro exemplo mais próximo de nossa realidade, trazido por Débora de Matos (2009), é a figura do Hotxuá, ainda vivo, que está presente na cultura da tribo brasileira dos Krahô localizada no estado do Tocantins, e assume funções semelhantes aos Heyokas. O Hotxuáé reconhecido como um verdadeiro sacerdote do riso, um curandeiro do corpo e da alma.

Observa-se, pois, que os tipos cômicos podem ser identificados em uma

${ }^{10}$ Na trajetória dos estudos sobre o cômico, na teoria do riso e na história do circo observa-se que, entre a bufonaria e a palhaçaria, muitas das atrações abusaram da ridicularização das diferenças humanas, expondo sujeitos com seus corpos, os quais não se enquadravam num padrão social. Jean-Jaccques Courtine (2008a, 2008b) escreveu acerca da exibição dessa corporalidade tida como "anormal" nas apresentações de circo. Citam-se aqui também os freek shows, por exemplo. Esse abuso, essa abordagem violenta contra os artistas, pode ser visto ainda no curta metragem Circo das Borboletas, disponível em: $\underline{\text { irco das Borboletas }}$ - HD (Legendado português) - YouTube. Acesso em: 22 mar. 2021. 
diversidade de rituais e em distintas comunidades, aldeias e tribos. Em diferentes tempos históricos e localizações geográficas, pouco a pouco, os cômicos foram ganhando destaque em seu ofício. Faraós, imperadores, nobres, príncipes e reis faziam questão de ter com exclusividade um cômico ao seu lado, pois se sentiam mais poderosos garantindo riso e diversão para seus convidados em casamentos, batizados, festas, dentre outros.

Na Idade Média, por exemplo, encontraram-se relatos sobre os bobos e bufões, tipos cômicos fundamentais para se compreender um pouco mais sobre a formação e a função social do palhaço.

O bufão é o grotesco. Manifesta exageradamente os sentimentos humanos. É malicioso e ingênuo, puro e cruel, romântico e libidinoso. Suas deformações físicas e seu modo de ser são como a manifestação física do tumor, da lepra das relações sociais e da pequenez humana. Seu comportamento é quase agressivo, propositadamente chocante. Ele não tem vergonha e, assim, desde suas necessidades fisiológicas básicas até o sexo, ele os faz em público de maneira descompromissada e provocadora (Burnier, 2001, p. 216).

Com a citação de Luís Otávio Burnier (2001), podem-se perceber várias semelhanças entre os bufões e os palhaços, como: a manifestação exagerada dos sentimentos humanos, a malícia e a ingenuidade. Como está sendo abordado outro contexto histórico-cultural, é relevante destacar: não é possível afirmar que os bufões e os bobos eram atores medievais e interpretavam personagens, porque não havia essa noção entre eles. Muito pelo contrário, apresentavam-se, assim, como cômicos, não somente no palco, mas viviam continuamente sendo bufões e bobos em todas as circunstâncias da vida. De maneira distinta, acredita-se que essa é uma característica presente nos palhaços, e que, embora a maioria utilize uma máscara na apresentação, também não representa necessariamente uma personagem e, sim, mostra ao público o íntimo de suas emoções expondo a intimidade de seu próprio ridículo.

Nesse contexto, Burnier (2001) afirma que o palhaço é um herdeiro do bufão, pois possui uma maneira diferenciada de pensar, bem como evidenciar algumas características próprias da pessoa. Estas são notadas também em aspectos da materialidade cênica, tais como a roupa exagerada, a maquiagem e o nariz 
vermelho. Para Burnier (2001), o palhaço seria um bufão sofisticado.

Castro (2005), por sua vez, ressalta que geralmente os cômicos medievais, como os bufões e os bobos: possuíam deformidades corporais, como a falta de um membro; eram gigantes, anões, cegos, corcundas; ou ainda, eram considerados loucos. Por se diferirem dos corpos ditos normais, esses cômicos eram vistos como seres inferiores. Paradoxalmente, tal inferioridade facilitava a aceitação de seu comportamento ousado e suas críticas sociais. Assim, eles passaram a ter um importante papel social, na medida em que eram muitas vezes requisitados para tecer críticas aos governantes e, ao mesmo tempo, utilizavam de seu humor para questionar as decisões tomadas pelos soberanos, de modo a fazê-los refletir sobre a forma como governavam.

O bufão era a única figura na corte que falava o que queria e bem entendia sem grandes problemas, mesmo colocando sua vida a prêmio. O pressuposto era: nada aconteceria a ele desde que todos rissem de suas bobagens. Não foram encontrados registros sobre mortes de cômicos após as apresentações.

\begin{abstract}
A história conservou o nome de Yu Sze, bufão do Imperador Shih HuangTi, que no ano de 300 A. C. promoveu uma reforma completa na grande muralha. O trabalho era intenso e realizado em condições tão adversas que milhares de trabalhadores morreram de fome e frio. O Imperador insistiu em continuar a obra a todo custo e cismou que era preciso pintar a muralha em toda sua extensão. É nesse momento que Yu Sze entra para história. Não sabemos exatamente que cena ele fez, mas graça a sua representação de como ficaria a China com a morte de mais trabalhadores, o Imperador suspendeu a pintura da muralha e o palhaço Yu Sze virou um herói nacional (Castro, 2005, p. 21).
\end{abstract}

A autora afirma que, desde sua origem, o bufão - assim como o palhaço surgiu como um ser social e político, utilizando do riso e das emoções humanas, para estabelecer comunicação com as autoridades, deixando, assim sua opinião, e participar dos rituais sagrados. Então:

O palhaço não é um personagem exclusivo do circo. Foi no picadeiro que ele atingiu a plenitude e finalmente assumiu o papel de protagonista. Mas o nome palhaço surgiu muito antes do chamado circo moderno. Aliás, seria melhor dizer os nomes. Uma das grandes dificuldades que a maioria dos autores encontra ao estudar a origem dos palhaços está na profusão de nomes que essa figura assume em cada momento e lugar. Clown, 
grotesco, truão, bobo, excêntrico, tony, augusto, jogral, são apenas alguns dos nomes mais comuns que usamos para nos referir a essa figura louca, capaz de provocar gargalhadas ao primeiro olhar (Castro, 2005, p. 11).

Percebe-se que as nomenclaturas acerca da figura do palhaço podem se modificar de acordo com o decorrer da história e, por isso, procura-se identificar os tipos cômicos que podem ter influenciado a ideia de palhaço que se conhece hoje. É preciso levar em consideração que existem traços do palhaço presentes em tipos cômicos que pertenceram a várias culturas antigas, e estes participavam de rituais sagrados, imitando coxos, cegos, leprosos, etc. Ao usar o riso como defesa de seus próprios medos, também ocupava papel de representação social, e não somente representava um papel social.

Os tipos característicos da baixa comédia grega e romana; os bufões e bobos da Idade Média; os personagens fixos da Commedia dell'Arte italiana; o palhaço circense e o clown possuem uma mesma essência: colocar em exposição a estupidez do ser humano, relativizando normas e verdades sociais (Burnier, 2001, p. 206).

A irreverência, a crítica à sociedade, e a exposição do próprio ridículo desses tipos cômicos citados acima estão presentes no palhaço que se conhece atualmente. O papel social destas figuras todas vem contribuindo diretamente com o trabalho do palhaço na contemporaneidade - seja pela máscara e maquiagem, seja pelas vestimentas, seja pelas técnicas da performance, entre outros.

Até aqui, percebem-se as múltiplas possibilidades de se compreender as origens da palhaçaria, cujos agenciamentos são rizomáticos ${ }^{11}$ e perpassam por vários tipos cômicos, encontrados em muitas culturas e tempos históricos diferentes. O tecido rizomático flexível está relacionado com os agenciamentos

\footnotetext{
${ }^{11}$ A partir das leituras de Mil Platôs (Deleuze \& Guattari, 1995) compreendemos o conceito de rizoma também como uma prática da estratoanálise, a qual se entende como o contrário de estratificar e, portanto, tratase de desestratificar. Ou seja, não permanecermos calcados em estados inalterados e tampouco dispostos em conceitos sedimentares, molares, enrijecidos, cristalizados. Na prática da estratoanálise, proposta pelos autores, resultam-se práticas como da anti-genealogia, contrário ao modelo arbóreo, ou seja, afirmam-se rizoma e o mapa, para possíveis agenciamentos. Nas palavras dos autores: "Para os estratos que fazem dele [tecido rizomático], sem dúvida, uma espécie de organismo, ou bem uma totalidade significante, ou bem uma determinação atribuível a um sujeito, mas ele não é menos direcionado a um corpo sem órgãos, que não pára de desfazer o organismo, de fazer passar e circular partículas a-significantes, intensidades puras, e não pára [sic] de atribuir-se os sujeitos aos quais não deixam senão um nome como rastro de intensidade" (Deleuze; Guattari, 1995, p.12).
} 
que são feitos, que por sua vez, são encontros de categorias e de conceitos os quais se desenrolam a partir do constructo do conhecimento acerca do objeto de pesquisa.

Nessa perspectiva multidimensional reconhece-se que todos os sujeitos participantes do movimento histórico do circo, colaboram para essa multiplicidade de abordagens, culminando na figura que hoje se conhece como palhaço. Além disso, pode-se afirmar que não só as linhagens do palhaço são inúmeras, como também as tipologias identificadas na arte da palhaçaria são constituídas nas muitas possibilidades de suas gênesis. Por esse motivo, a seguir, buscaram-se identificar alguns dos tipos de palhaços, tidos como clássicos, que foram surgindo ao longo da história, e quais são suas principais características.

\section{Poesias e bobagens - identificando os tipos de palhaços}

Tentar categorizar os tipos de palhaços é uma tarefa não conclusiva, uma vez que as tipologias são flexíveis e, sofrem transformações ao longo do tempo, de acordo com o contexto histórico e a dinâmica cultural. Dito isso, acredita-se que o palhaço é o próprio sujeito, formado por suas experiências individuais e coletivas concomitantemente. Porém, não se ignoram os principais tipos clássicos da palhaçaria, que são: o Palhaço Branco, o Palhaço Augusto, e o Palhaço ContraAugusto.

Antes de se entrar nos tipos clássicos de palhaços, faz-se necessário evidenciar que a figura do mestre de pista não se caracteriza como um tipo de palhaço, mas está presente em alguns números da arte da palhaçaria, apesar de não ser necessariamente o responsável pela comicidade da apresentação. mestre de pista geralmente está presente no espetáculo de variedades, do circo tradicional'12. É o nome dado ao apresentador, o qual é o responsável pelo gerenciamento e andamento do espetáculo circense. Além de apresentador, o

12 Gostaríamos de ressaltar, que não é em todo circo "tradicional contemporâneo" que encontramos a figura do mestre de pista, pois, por vezes, ela é inserida e exercida por um palhaço Branco ou Augusto. Embora pareça contraditório, no termo "tradicional contemporâneo", residem justamente as contradições que notamos nas pesquisas mais recentes acerca do circo tradicional e do circo contemporâneo, pensando que ambos são presentes na nossa contemporaneidade e possuem suas interlocuções. 
mestre de pista é um diretor em cena, autoridade máxima no picadeiro, figura capaz de improvisar e garantir que o espetáculo siga seu curso mesmo diante dos mais insólitos imprevistos. Pode-se apontar Philip Astley como seu precursor, levando-se em consideração todos os aspectos apresentados anteriormente sobre o circo moderno.

Bolognesi (2003) ressalta que, de início, esse tipo era representado pelo próprio dono do circo e, durante muitos anos, foi prerrogativa dos adestradores de cavalo. Como o espetáculo era centrado nas exibições equestres, o mestre de pista usava um longo chicote, um apito na boca e dirigia os animais em cena. Coerentemente com suas origens militares, o circo tradicional tinha no mestre de pista a figura símbolo do poder, o grande responsável pela ordem e pela tranquilidade da condução do espetáculo.

Analisando-se agora os tipos do palhaço Branco e do palhaço Augusto, é preciso primeiramente compreender alguns fatores. Começa-se citando que, durante o século XIX, o circo moderno europeu sofreu com os limites impostos pelas normas e leis que controlavam/censuravam os espetáculos. Logo, os palhaços podiam falar apenas pequenas frases e não podiam nem tocar instrumentos. Em tal contexto, houve um grande desenvolvimento de criação de repertório cênico, com aprimoramento de cenas realizadas sem o recurso da voz. Ou seja, cenas mudas, nas quais os palhaços utilizavam da mímica, da pantomima e da teatralidade em suas construções.

Para suprir o uso da palavra, esses palhaços investiram em várias técnicas, principalmente nas acrobacias, tornando-se primeiramente grandes palhaços acrobatas, que realizavam números com cavalos. Com o tempo, houve a diminuição dos cavalos no programa do espetáculo de Astley. Em contrapartida, houve o aumento das representações junto com as acrobacias; e a fala e o diálogo foram também se ampliando nos números dos palhaços. Assim, além de realizar seus números com cavalos, o palhaço assumiu a função de costurar as cenas do espetáculo, surgindo, segundo Silva (2008, p.48), o clown-parleur.

Quando o artista que representava o cômico foi ganhando também direito à pantomima falada, tornou-se o que se costuma chamar de clown- 
parleur, personagem que, para alguns autores, começou a se posicionar com um ar de superioridade entre os clowns saltadores.

Esse clown-parleuré identificado com o chamado Palhaço Branco, visto que, após analisar as características e funções colocadas acerca deste nome, percebese que ambos possuem características semelhantes.

A transformação do papel do palhaço no circo ocorreu, portanto, quando o palhaço ganhou direito à fala. Nesse momento, o Branco se apropria de uma de suas principais características que é a superioridade diante dos palhaços acrobatas. Superioridade esta que ganhará força quando o Branco se solidificar como parceiro do palhaço Augusto. Para entendermos melhor esta construção recorremos a seguinte colocação de Burnier (2001, p. 206):

Existem dois tipos clássicos de clowns: o branco e o augusto. O clown branco é a encarnação do patrão, o intelectual, a pessoa cerebral. Tradicionalmente, tem rosto branco, vestimenta de lantejoulas (herdada do Arlequim da Commedia dell'arte), chapéu cônico e está sempre pronto a ludibriar seu parceiro em cena. Mais modernamente, ele se apresenta de smoking e gravatinha borboleta e é chamado de cabaretier. No Brasil, é conhecido por escada.

O autor referencia os dois principais tipos clássicos de palhaço e mostra claramente algumas características tradicionais do palhaço Branco e, ao final, traz o termo 'escada'. No Brasil, o palhaço Branco assume o papel de iniciar a piada para o seu parceiro - Augusto - arrematar e concluí-la com veemência, ou seja, ele assume o papel de escada ou crom. Bolognesi (2003) diz que o palhaço Branco tem como característica a boa educação, refletida na fineza dos gestos, e a elegância nos trajes e nos movimentos. É um burguês, que de entrada, procura surpreender com sua aparência de rico, poderoso e, maravilhoso e, possui graça, harmonia, inteligência, e lucidez, sendo o moralista, que tem ideais.

Frederico Fellini (1970), em seu filme I Clowns ${ }^{13}$, explica que os palhaços Brancos eram homens muito duros; e fala sobre Antonet, um afamado palhaço

13 Filme cuja temática principal é a palhaçaria. Com direção de Frederico Fellini (1970), I Clowns é uma junção de ficção, documentário e depoimento pessoal, seguindo um formato híbrido. Disponível em: https://www.youtube.com/watch?v=hqu7jxHHsm8 Acesso em: 16 fev. 2021. 
Branco. Fora de cena, Antonet nunca dirigiu a palavra a seu parceiro Beby - um palhaço Augusto - devido à relação que eles estabeleceram. No filme, fica explícita a seguinte regra na interação entre o Branco e o Augusto: o Branco tem que ser malvado, aquele que dá bofetadas.

Então, em oposição ao palhaço Branco, tem-se o palhaço Augusto, e sua marca característica é o nariz vermelho. Tradicionalmente, ele não pinta todo o rosto, procurando destacar os olhos e a boca, levando-se em consideração que o nariz já está em destaque. O Augusto se apresenta de forma desajeitada, rude e indelicado, e outra característica deste tipo é a estupidez.

O augusto (no Brasil, tony ou tony-excêntrico) é o bobo, o eterno perdedor, o ingênuo de boa fé, o emocional. Ele está sempre sujeito ao domínio do branco, mas, geralmente, supera-o, fazendo triunfar a pureza sobre a malícia, o bem sobre o mal. Afirma que a relação desses dois tipos de clowns acaba representando cabalmente a sociedade e o sistema, e isso provoca a identificação do público com o menos favorecido, o augusto (Burnier, 2001, p. 206).

Burnier cita algumas das características encontradas naquele que seria o Augusto, seus variados nomes, e elucida a relação social que este tipo representa.

Ainda sobre Augusto, existem algumas lendas sobre a sua criação; e vários autores, como Bolognesi (2003) e Castro (2005), colocam Tom Belling'14 (1873 1934) como precursor desta criação. Uma das versões diz que Belling era acrobata e, após sofrer uma queda, fora repreendido pelo dono do circo e proibido de se apresentar no picadeiro. Devido a essa proibição, o acrobata passava partes do seu tempo realizando travessuras com seus amigos. Certa noite, ele estava brincando com uma peruca e decidiu colocá-la de trás para frente. Acrescentou alguns nós, deixou-a armada, vestiu também um paletó velho ao avesso e decidiu se exibir. Quando estava a brincar com os amigos, Belling foi novamente repreendido pelo dono do circo, mas desta vez, o diretor achou fantástica aquela aparência cômica e decidiu, assim, devolvê-lo ao picadeiro com essa nova caracterização. Belling entrou desajeitadamente em cena, tropeçou caiu, e o nariz imediatamente inchou e ficou avermelhado. O público se deliciou com a cena e

${ }^{14}$ Tom Belling era acrobata, treinador de pequenos animais e palhaço, atuante no Circo Renz. 
começou a gritar, "Augusto!". Pelo ridículo da situação, sobre o termo Augusto, Bolognesi (2003, p. 73) diz:

O termo augusto tem sua raiz na língua alemã e foi utilizado pela primeira vez em 1869, em Berlim, quando Tom Belling, um cavaleiro, teve uma apresentação desastrosa no picadeiro. O público, então, gritou: "Augusto! Augusto!". August, em dialeto berlinense, designava as pessoas que se encontravam em situação ridícula, ou ainda aquelas que se faziam de ridículas.

Bolognesi (2003) aponta a primeira vez que o termo Augusto foi utilizado conforme uma das versões da criação deste tipo. Outra suposta versão apresentada por Roland Auget na obra Histoire et legende Du cirque, aponta que Belling se embriagou antes de se apresentar, prejudicando sua apresentação e seu equilíbrio no picadeiro. Belling entrou no picadeiro, vestindo trajes desproporcionais a seu tamanho e, por isso, provocou risos na plateia. A embriaguez teria sido responsável por deixar a face de Belling avermelhada, principalmente o nariz, que mais tarde seria o símbolo principal do palhaço.

O Augusto é exatamente o contrário do Branco: o Branco se mostra com aparência de rico e trabalha com perfeição; e o Augusto é o pobre desajeitado. A dupla de palhaço, Branco e Augusto, representa um aspecto estrutural da sociedade e da luta de classes. Enquanto o Branco promove a ordem e o dever, o Augusto representa o marginal. O palhaço Augusto nasce, portanto, nesta/ desta realidade: ele é pobre, humilde, mas não se deixa levar pelas adversidades, muito pelo contrário, brinca com a sua própria situação, caçoa com o tamanho exagerado de seu sapato e com a calça que se arrasta no chão.

Frederico Fellini (1970) afirma que o Branco e o Augusto são, respectivamente, a professora e o menino, a mãe e o filho arteiro; e até se podia dizer que o anjo com a espada flamejante e o pecador. São, em suma, duas atitudes psicológicas do homem, o impulso para cima e o impulso para baixo, divididos, separados. O palhaço Branco e o Augusto conquistaram suas identidades e, apesar de serem parceiros, suas funções e seus perfis os transformaram em tipos distintos, mas sempre completando um ao outro.

O palhaço Branco é aquele que comanda a cena e domina o acontecimento e, a partir de então, passa a ser a autoridade social, evocando as restrições dadas 
ao Augusto, apontando os limites. O Augusto, por sua vez, quebra as regras, ultrapassando os limites impostos pelo Branco.

Avançando nas explanações acerca dos tipos clássicos da palhaçaria, apresenta-se o chamado Contra-Augusto (Bolognesi, 2003). A criação do ContraAugusto é atribuída aos Irmãos Fratellini15 em 1909. O Contra-Augusto está entre dois extremos: o autoritarismo, a sublimidade, a inteligência e a delicadeza do Branco, e a tolice, a rudeza, a ingenuidade, o grotesco e a subordinação do Augusto. o Contra-Augusto é a legítima figura do 'puxa saco'.

O Augusto é um tipo simples e tem sua matriz ligada à vida campesina, enquanto o Branco tem suas aproximações com o mundo aristocrático. O ContraAugusto então surge no meio, como um pequeno burguês convencido de sua superioridade e pronto para cometer canalhices como o Branco. Concomitantemente, é dotado de simplicidade, ingenuidade, tolice e subordinação como o Augusto.

A dupla cômica estava muito consolidada, mas, com a criação de um terceiro tipo, as possibilidades de criação aumentaram, pois, a cena não iria ocorrer unicamente envolta do jogo dos opostos (Branco e Augusto). Ou seja, os opostos aparecem por proporcionarem possibilidades e condições para qualquer conflito cênico ou cena cômica, com o Contra-Augusto as possibilidades de resolver esses conflitos aumentaram e deixaram o jogo mais complexo, com mais variantes.

Um terceiro tipo - o qual apresenta características físicas e morais definidas, mas que transita entre as qualidades e os defeitos dos parceiros em situação de oposição - traz implicações diversificadas e, ao mesmo tempo, mais possibilidades de avanço no desempenho da apresentação.

O circo moderno brasileiro não possui uma tradição acentuada acerca do palhaço Branco em seus espetáculos. Contou a função do palhaço Branco sempre se manteve presente, absorvida nas apresentações cômicas pelo mestre de pista, por outro Augusto ou até mesmo pelo Contra-Augusto. Sobre a predominância do Augusto, no circo brasileiro, Bolognesi (2003, p.91) conclui:

15 O trio de palhaços dos irmãos Fratellini, fez grande sucesso, em 1923. Nascidos na Itália, mas com cidadania francesa, os irmãos trabalharam por muitos anos no Cirque Medrano, em Paris. 


\begin{abstract}
A pesquisa realizada nos circos brasileiros não encontrou nenhum Clown Branco. As suas funções foram absorvidas pelo apresentador (Mestre de Pista) ou por um segundo palhaço, também ele um Augusto, chamado de escada ou crom. Os palhaços brasileiros da atualidade não têm mais as características externas dos primitivos clowns, embora tenham absorvido muitas das proezas por eles desenvolvidas. [...] Mantém-se, contudo, a permanência em cena de uma dupla de palhaços, ao menos. Em muitas situações há a presença de três cômicos em cena. Nesse caso, além da polaridade inicial, há a ação de um contra - Augusto, uma espécie de segundo palhaço com habilidades, contudo, para romper os limites físicos, emocionais e intelectivos que caracterizam o Augusto propriamente dito.
\end{abstract}

Comunga-se do pensamento de Bolognesi, pois, de fato não se encontra nos circos brasileiros o tipo do palhaço Branco tal qual em relação a sua indumentária brilhosa e a seu chapéu de cone. Mas, com toda certeza, a função exercida pelo Branco se mantém presente, pois sem ela se perderia o jogo estabelecido pela dupla ou trio cômico.

Afirma-se que esses tipos foram essenciais para a consolidação do palhaço na sociedade e extremamente importantes para a formação do palhaço na atualidade. Porém, ressalta-se que esses tipos servem de base para a criação do palhaço, o processo criativo de tal construção exige um mergulho pessoal a cada indivíduo, possuindo características específicas relacionadas à individualidade de cada sujeito.

Compreende-se até aqui, a relevância dos tipos clássicos da palhaçaria, inclusive se pensa que eles são uma base para a construção de cada palhaço. Todavia, não se acredita que se deva entendê-los de forma fechada e conclusiva. As distintas funções entre Branco, Augusto e Contra Augusto estão presentes nos palhaços e sempre estarão porque esses tipos retratam valores humanos e sociais e, portanto, sempre se farão presentes.

\title{
Na Corda Bamba - Considerações Finais
}

Pode-se perceber que o palhaço se transfigura de acordo com o tempo e o lugar, contendo em si uma historicidade. Na teoria e na prática, ele se cria e é 
criado por meio das experiências de vida dos seus criadores. Já no título "(Trans)formações do palhaço". "Trans" é justamente no sentido de: conhecer, por diversas fontes, a arte da palhaçaria; e transitar por entre zonas diversas de formação da figura do palhaço. Deste modo, se identificará e refletirá criticamente sobre como essas distinções vêm influenciando e podem vir a influenciar a própria formação do palhaço.

Assim, nota-se que o conhecimento acerca da arte dos tipos cômicos é transversal e atravessa várias áreas do conhecimento, como: circo, teatro, história, cinema, antropologia, filosofia, sociologia, dentre outras. Ou seja, a formação do palhaço e as transformações no que dizem respeito à sua figura estão relacionadas com essa inter-relação das diversas áreas do conhecimento. Talvez por isso seja tão difícil categorizar essa figura, o que também não é nosso intuito.

Neste trabalho, trouxemos possibilidades de descoberta de alguns dos tipos cômicos que pudessem nos apontar traços importantes na construção do palhaço historicamente. Sem a pretensão de encontrarmos um ponto fixo, ou uma referência específica, o que trazemos ao analisar esses traços, foram caminhos possíveis para compreendermos como o palhaço está ligado ao ser humano em seu desenvolvimento social. Destarte, as figuras cômicas estão ligadas a diferentes culturas, comunidades, coletivos, tribos, enfim, a lugares nos quais os homens se reúnem. Seja para tomar decisões, ritualizar, divertir ou criticar, sempre existirá uma figura cômica, pois o homem tem a necessidade de rir e de fazer-se rir. $O$ riso para expurgar as almas, o riso para enfrentar os medos, o riso para questionar os poderosos.

Apontamos os principais tipos clássicos de palhaços, investigando o jogo proposto com/por eles, especialmente o Branco e o Augusto. Pudemos perceber que tais triangulações entre a dupla e a plateia nos colocam diante de uma realidade a qual tenciona aspectos das classes sociais. Ou seja, o palhaço tantas vezes se volta para questões inerentes à estrutura societal, quanto é constituído nas/pelas forças e em relações de poder presentes nas sociedades. Mas, na provocação do riso e na busca pela comicidade, o melhor caminho seria a ingenuidade do Augusto, a empáfia do Branco ou o oportunismo do ContraAugusto? 
Em diferentes contemporaneidades e contextos conseguimos observar características desses tipos clássicos na (per)formação dos artistas que trabalham com o cômico. Mas não é porque o clássico determina necessariamente todas as práticas da palhaçaria - mesmo porque não são as únicas referências, como já dito anteriormente; e tais tipos clássicos aqui elencados emergem com o dito circo tradicional moderno - e sim porque o clássico se fez ou se faz na experiência da própria práxis do circo moderno e extemporâneo reconfigurando-se em nossa contemporaneidade, portanto.

Fazer rir é uma tarefa árdua, bem como: rir de si mesmo e consigo mesmo; rir dos outros, com os outros e para os outros, que são nossos espelhos. As metodologias, as técnicas, as poéticas que nós palhaços estudamos e experienciamos para levar o público ao riso e para levar o riso ao público são diversas, também passam por transformações. Deste modo, como o ser humano muda, as relações com o que é risível também se transformam. E o sujeito, por sua vez, forma-se também por meio do riso e da comicidade, da mesma maneira que o cômico se forma na historicidade crítica, ainda que seja clássica.

\section{Referências}

AUGUET, Roland. Historie et legende du cirque. Paris: Flammarion, 1974.

BERGSON, Henri. O riso: ensaio sobre a significação da comicidade. Trad. Ivone Castilho Benedetti. 2a ed. São Paulo: Martins Fontes, 2007.

BOLOGNESI, Mário Fernando. Palhaços. São Paulo: Editora UNESP, 2003.

BURNIER, Luís Otávio. A arte de ator: da técnica a representação. Campinas, SP: Editora da Unicamp, 2001.

CASTRO, Alice Viveiros de. Elogio da Bobagem. Rio de Janeiro: Editora Família Bastos, 2005.

COURTINE, Jean-Jacques. O corpo inumano. In: CORBIN, Alain; COURTINE, JeanJacques; VIGARELLO, George (orgs.). História do Corpo. (Vol. 1.Da Renascença às Luzes). Tradução: Lúcia M.E. Orth. Petrópolis: Editora Vozes, 2008a, p.487-502.

COURTINE, Jean-Jacques. O corpo anormal - História e antropologia culturais da deformidade. In: CORBIN, Alain; COURTINE, Jean-Jacques; VIGARELLO, George (org.). História do Corpo. (Vol. 3. As Mutações do Olhar: O Século XX). Tradução e 
revisão: Ephraim Ferreira Alves. Petrópolis: Editora Vozes, 2008b, p.253-340.

DELEUZE, Gilles e GUATTARI, Félix. Mil Platôs: capitalismo e esquizofrenia. Vol. 1. Tradução: de Aurélio Guerra Neto, Celia Pinto Costa. São Paulo: Editora 34, 1995.

FO, Dario. Manual Mínimo do ator. São Paulo: Editora Senac, 1998.

I CLOWNS. Direção: Federico Fellini. Produção: Elio Scardamaglia. Local: Itália. 1970.

MATOS, Débora de. A formação do palhaço: Técnica e pedagogia no trabalho de Ângela de Castro, Ésio Magalhães e Fernando Cavarozzi. 2009. Dissertação (Mestrado em Teatro) - Centro de Artes - Universidade do Estado de Santa Catariona, Florianópolis, 2009.

PAVIS, Patrice. Dicionário de teatro. Tradução para a língua portuguesa sob a direção de J. Guinsburg e Maria Lúcia Pereira. São Paulo: Perspectiva, 1999.

Sena, Jonathan Brites. (Trans) Formações Do Palhaço: História Dos Tipos e Técnica na Arte da Palhaçaria. 2014. Trabalho de Conclusão de Curso. Universidade Federal de Goiás, 2014.

SILVA, Ermínia. Circo-Teatro: Benjamim de Oliveira e Teatralidade Circense no Brasil. São Paulo: Editora Altana, 2008.

THE BUTTERFLY CIRCUS [O Circo das Borboletas]. Direção: Joshua Weigel. Produção: Joshua Weigel, Rebeca Weigel, Angie Alvarez. Local: Estados Unidos da América. 2009. 